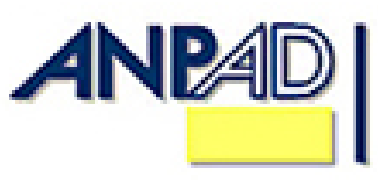

Disponível em http://www.anpad.org.br/rac

RAC, Rio de Janeiro, v. 16, n. 3, pp. 484-488, Maio/Jun. 2012

$(\mathrm{coc})$ EY-NC

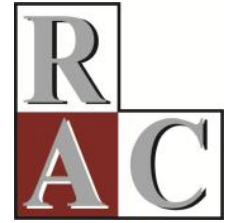

Documentos e Debates:

\title{
Réplica 2 - Sabemos a Lição, mas Ainda Não Aprendemos: Comentários sobre a Pesquisa Científica da Área de Marketing, no Brasil
}

We Know the Lesson, but We Haven't Yet Learned It: Commentary about Brazilian Scientific Research in Marketing

Francisco Giovanni David Vieira *

E-mail: fgdvieira@uem.br Universidade Estudual de Maringá - PPA/UEM Maringá, PR, Brasil.

\footnotetext{
* Endereço: Francisco Giovanni David Vieira Universidade Estadual de Maringá, Centro de Ciências Sociais Aplicadas, Departamento de Administração, Av. Colombo, 5790, Bloco C-23, Sala 207, Zona 7, Maringá/PR, 87020-900.
}

Copyright (C) 2012 RAC. Todos os direitos, até mesmo de tradução, são reservados. É permitido citar parte de artigos sem autorização prévia, desde que seja identificada a fonte. 


\section{Introdução}

Desde os anos 1990, a Revista de Administração Contemporânea (RAC), por meio de sua seção Documentos, vem estimulando a reflexão e o diálogo em torno de temas de interesse da comunidade acadêmica brasileira no campo da Administração e, por conseguinte, na área de Marketing. A promoção de debates a partir da publicação de documentos, bem como das réplicas e tréplicas a eles relacionadas, não só fundou um espaço editorial inédito na academia brasileira de administração, como demarcou uma condição de leitura imperativa para pesquisadores. Estar envolvido na produção de conhecimento em administração, no Brasil, requer estar atento aos documentos, réplicas e tréplicas publicados na RAC.

Sob esse ponto de vista, agradeço ao convite formulado pelo Professor Jaime Fensterseifer para escrever uma réplica acerca do documento Pesquisa Acadêmica da Área de Marketing no Brasil: uma Revisão dos Anos 2000, escrito por Sampaio et al. (2012). A rigor, tal documento é o quarto de uma série iniciada nos anos 2000 (Froemming et al., 2000a, 2000b; Sampaio \& Perin, 2006), e que trouxe considerável contribuição para o entendimento da produção científica na área de marketing em nosso país. O terceiro documento contou, inclusive, com profícua e ampla réplica de Mello (2006).

O principal mérito do documento mais recente (Sampaio et al. 2012) consiste em, por um lado, proporcionar uma visão longitudinal da produção da área de marketing; e, por outro, permitir uma análise comparativa de tal produção ao longo dos anos. É preciso reconhecer que não é um feito simples produzir um estudo envolvendo um período de 20 anos de análise, sobretudo usando como procedimento para análise o mesmo conjunto de variáveis. É bem provável que esse seja o único estudo produzido no Brasil, no campo da Administração, com tais características.

A compreensão da produção científica em uma área de conhecimento, todavia, sempre apresenta diversas nuanças e aspectos que podem ser observados de diferentes ângulos. Os comentários que aqui apresento, antes de alimentarem o exercício da polêmica em torno de descaminhos, visam a ampliar o debate sobre os caminhos da produção científica em marketing, no Brasil. A tese aqui defendida, e engendrada a partir da leitura de Sampaio et al. (2012), é a de que conhecemos, mas ainda não aprendemos a lição atinente à produção científica em marketing, no Brasil. Posto isso, o presente texto encontra-se dividido em três momentos: no primeiro, aponto, de forma concisa, o que considero ser os principais achados de Sampaio et al. (2012); no segundo, apresento comentários sobre tais achados, procurando abordá-los por ângulos distintos ou complementares; no último momento, realizo considerações finais sobre o documento e, sobretudo, indico o que considero ser a questão central da produção científica em marketing, no Brasil, atualmente.

\section{Os Principais Achados do Artigo}

De acordo com Sampaio et al. (2012), após a avaliação de 1.317 artigos de base empírica, publicados nos principais periódicos de administração brasileiros, segundo a classificação do sistema QUALIS da CAPES, e com base em 16 dimensões de análise, houve um avanço no que se refere a critérios de qualidade relacionados às características metodológicas básicas da produção científica brasileira na área de marketing, ao longo dos anos 2000. Além de uma maior diversidade temática na produção observada, foi possível perceber uma maior busca da base conceitual na realização das pesquisas. Em linhas gerais, tais aspectos apontam na direção de uma produção científica de melhor qualidade.

Os resultados que informam Sampaio et al. (2012) para essas conclusões estão alicerçados nas seguintes observações relativas à produção dos anos 2000: (a) fez-se mais pesquisas do tipo experimental (quase três vezes mais); (b) fez-se mais pesquisas de natureza causal (quase quatro vezes mais); (c) apresentaram-se de forma mais aprofundada teorias de base adotadas na pesquisa; (d) 
apresentou-se mais a operacionalização de variáveis (quase duas vezes mais); (e) procurou-se, com maior frequência, proceder a validade externa das pesquisas, bem como a validade nomológica das escalas nelas utilizadas (quase três vezes mais em ambos os casos). Por sua vez, embora tenha sido percebido um aumento na apresentação de recomendações para pesquisas, houve importante redução na apresentação de recomendações aplicadas. Por fim, cabe destacar que houve redução no número de artigos de ordem conceitual e que houve aumento tanto na utilização de dados primários quanto de dados secundários na condução das pesquisas.

\section{Comentários sobre o que Foi Encontrado e outras Palavras}

Os resultados encontrados por Sampaio et al. (2012), em tão longo estudo, evidenciam um desafio para pesquisadores da área de marketing no Brasil. Comento alguns desses resultados, logo a seguir, em forma de tópicos.

Equações e experimentos. O crescimento da pesquisa do tipo experimental, no Brasil, reflete, em boa medida, o movimento editorial de grandes periódicos da área de marketing, como, por exemplo, o Journal of the Academy of Marketing Science e o Journal of Marketing Research. Parece refletir, também, movimento semelhante àquele observado no final dos anos 1990, em que utilizar modelagem por meio de equações estruturais sugeria estar na fronteira do conhecimento metodológico em pesquisas da área de marketing. Sugere, ainda, uma tentativa de se aumentar a possibilidade de publicação internacional. O problema com o aumento desse tipo de pesquisa, no Brasil, é que ele se dá, basicamente, por meio de experimentos realizados com estudantes universitários, em salas de aula ou laboratórios de informática das instituições de ensino. Portanto é um tipo de pesquisa que tem o alcance das fronteiras de uma sala de aula e que representa uma espécie de resgate da Psicologia Behaviorista. Mal entendemos de Psicologia Social que, via de regra, não é ministrada em nossos cursos de pós-graduação, mas queremos conduzir experimentos.

Enxerga-se o consumidor, mas fecha-se a cortina para a gestão. $\mathrm{O}$ enorme crescimento das pesquisas de natureza causal está associado principalmente a estudos sobre comportamento de consumo. Curiosamente, acadêmicos brasileiros de marketing não estudam, com frequência, a gestão em marketing. São raras as pesquisas que tratam de gestão de marketing, muito menos aquelas cuja natureza é causal. O crescimento da pesquisa de natureza causal, portanto, é limitado em seu escopo.

Uso de teorias como mimetismo. A maior presença da informação sobre teorias de base nos artigos publicados, nos anos 2000, pode não estar relacionada ao aumento de pesquisas do tipo experimental e de natureza causal, as quais, segundo Sampaio et al. (2012), exigem maior aprofundamento teórico. Com efeito, todas as pesquisas, pelo menos em tese, exigem aprofundamento teórico. É de se supor que tais informações estejam mais presentes como um processo de mimetização da forma de publicação dos artigos do Journal of Consumer Research, Journal of Marketing, Journal of Marketing Research e Journal of the Academy of Marketing Science. O formato e estrutura dos artigos publicados no Brasil, na área de marketing, se parecem cada vez mais com o formato e estrutura dos artigos desses periódicos, o que inclui a explicitação das teorias de base que os orientam.

Operacionalização de variáveis em detrimento de categorias analíticas. O crescimento na operacionalização das variáveis reflete o viés mais positivista da pesquisa científica em marketing no Brasil. A ampliação da oferta de disciplinas de análise multivariada em programas de pós-graduação, que não é acompanhada, pari passu, pela oferta de disciplinas de métodos qualitativos, ajuda a explicar o trabalho com variáveis e suas operacionalizações em detrimento, por exemplo, do trabalho com categorias analíticas, em tese, mais amplas e compreensivas.

Com mais rigor, porém menos relevância. A preocupação com a validade das pesquisas é condição imperativa para a produção do conhecimento (Varadarajan, 2003). O que tem acontecido, entretanto, é que a área de marketing no Brasil faz uma escolha pelo rigor em detrimento da relevância 
(Faria, 2007). O resultado tem sido um distanciamento cada vez maior do que se executa no cotidiano das organizações empresariais, assim, sendo perceptível a redução no número de recomendações aplicadas. Acadêmicos de marketing constroem um mundo à parte e distanciam-se de praticantes.

A um passo da eternidade. Embora discreto, o aumento no uso de dados primários parece manter uma relação com o aumento do uso de experimentos, bem como de uma maior incidência de pesquisas de natureza causal. $\mathrm{O}$ uso recente de dados primários tem sido apoiado, com grande frequência, pela coleta de dados por meio da internet. Com isso, na expectativa de poder generalizar os resultados da pesquisa e ir além-mar, pesquisadores têm cometido erros básicos de amostragem, com dados viciados e nada probabilísticos (Summers, 2001). Um outro problema é que dados primários nas pesquisas em marketing, no Brasil, especialmente aquelas relacionadas a experimentos, é sinônimo de dados de estudantes universitários, que, a despeito de possíveis questões éticas na condução das pesquisas, têm recebido incentivos materiais e monetários para participar de experimentos. E, embora o trabalho com dados primários tenha sido mais valorizado do que o trabalho com dados secundários por acadêmicos de marketing, no Brasil (Kovacs, 2006), é salutar a observação de que, nos anos 2000, foram usados mais dados secundários do que nos anos 1990. Isso é algo promissor, pois o Brasil tem dimensões territoriais e seria aconselhável desenvolver com maior intensidade uma cultura de trabalho com dados secundários, cujo custo de coleta, a princípio, é mais barato.

É preciso aprender a pensar. É curiosa a queda gradativa no percentual de artigos conceituais publicados nos anos 2000. Antes de qualquer outro aspecto, parece indicar resistência à pesquisa conceitual e ao exercício de se pensar marketing enquanto área de conhecimento. Um exemplo eloquente dessa possibilidade está atrelado aos painéis promovidos nos encontros acadêmicos, como, por exemplo, nos EnANPADs de 2008 e 2010. Dos quais, tive a oportunidade de assistir ao primeiro e participar do segundo como debatedor, percebendo, assim, que é nítida a ausência e o desinteresse de pesquisadores da área nesses painéis. A queda na produção de artigos desse tipo pode, também, resultar-se de uma indução para a produção de artigos com viés positivista, que obtêm maior taxa de aceite em periódicos. $\mathrm{O}$ artigo conceitual é visto como um artigo de segunda categoria. Isso colabora para que não se pense a área ou temáticas da área. Parte importante do conhecimento de marketing foi produzida por meio de trabalhos conceituais (Faria, 2006; Rossi \& Farias, 2006) e consideráveis são os desafios que precisam ser compreendidos atualmente e que poderiam ser objeto de trabalhos conceituais (Araujo, Finch, \& Kjellberg, 2010).

\section{Considerações Finais}

O artigo de Sampaio et al. (2012) brinda-nos com importante levantamento da pesquisa científica na área de marketing, no Brasil, nos anos 2000, e nos mostra que, do ponto de vista metodológico, produzimos melhores pesquisas hoje do que no passado. Não obstante a importância do estudo aqui analisado, percebe-se que a pesquisa em marketing, no Brasil, caracteriza-se pelo mimetismo e pela busca de padrões metodológicos científicos de aceitação para publicação editorial em periódicos e, assim, tem prezado mais o rigor em detrimento da relevância. Desse modo, é uma pesquisa que se refina e revela, pouco a pouco, que os pesquisadores de marketing vêm tomando conhecimento de como produzir conhecimento sob critérios metodológicos mais consistentes, porém, paradoxalmente, ainda não aprenderam a fazer isso de forma relevante.

Após esse passo inicial é preciso que a pesquisa científica em marketing, no Brasil, busque uma identidade e apresente uma agenda que reflita o nosso mercado; e não os desígnios do Marketing Science Institute, o que inclui: (a) estudar pequenas e médias empresas; (b) olhar para a gestão e práticas de marketing; (c) não fazer da multidisciplinaridade um mero discurso; (d) não abdicar das discussões conceituais; e (e) valorizar a pesquisa qualitativa. 


\section{Referências}

Araujo, L., Finch, J., \& Kjellberg, H. (2010). Reconnecting marketing to markets. Oxford: Oxford University Press.

Faria, A. A. de (2006). Crítica e cultura em marketing: repensando a disciplina. Cadernos EBAPE.BR, $4(3), 1-16$.

Faria, A. A. de (2007). Relevância ou rigor? GV Executivo, 6(3), 39-43.

Froemming, L. M. S, Luce, F. B., Perin, M. G., Sampaio, C. H., Beber, S. J. N., \& Trez, G. (2000b). Análise da qualidade dos artigos científicos da área de marketing no Brasil: as pesquisas survey na década de 90. Revista de Administração Contemporânea, 4(3), 201-219. doi: 10.1590/S141565552000000300011

Froemming, L. M. S., Luce, F. B., Perin, M. G., Sampaio, C. H., Beber, S. J. N., \& Trez, G. (2000a). Inventário de artigos científicos na área de marketing no Brasil. Revista de Administração Contemporânea, 4(2), 159-173. doi: 10.1590/S1415-65552000000200009

Kovacs, M. H. (2006, maio). Entre o fusca zero bala e o jaguar usado: uma reflexão crítica da (não) utilização de dados secundários em pesquisas na área de marketing. Anais do Encontro de Marketing da ANPAD, Rio de Janeiro, RJ, Brasil, 2.

Mello, S. C. B. de. (2006). Comentários: o que é o conhecimento em marketing no Brasil, afinal? Revista de Administração Contemporânea, 10(2), 203-212. doi: 10.1590/S141565552006000200011

Rossi, C. A. V., \& Farias, S. A. (2006). Conhecimento científico em marketing no Brasil: perspectivas para o desenvolvimento da pesquisa e teoria. Revista de Administração de Empresas, 46(4), 1012. doi: $10.1590 / \mathrm{S} 0034-75902006000400002$

Sampaio, C. H., \& Perin, M. G. (2006). Pesquisa científica da área de marketing: uma revisão histórica. Revista de Administração Contemporânea, 10(2), 179-202. doi: 10.1590/S141565552006000200010

Summers, J. O. (2001). Guidelines for conducting research and publishing in marketing: from conceptualization through the review process. Journal of the Academy of Marketing Science, 29(4), 405-415. doi: 10.1177/03079450094243

Varadarajan, P. R. (2003). Musings on relevance and rigor of scholarly research in marketing. Journal of the Academy of Marketing Science, 31(4), 368-376. doi: 10.1177/0092070303258240 